\title{
A Survey of Kurdish Students' Sound Segment \& Syllabic Pattern Errors in the Course of Learning EFL
}

\author{
Jahangir Mohammadi \\ Ministry of Education English Teacher, Sanandaj, Iran \\ E-mail: mohammadij3@gmail.Com
}

Doi:10.7575/aiac.alls.v.5n.3p.18

URL: http://dx.doi.org/10.7575/aiac.alls.v.5n.3p.18

\author{
Received: 01/04/2014 \\ Accepted: 04/05/2014
}

\begin{abstract}
This paper is devoted to finding adequate answers to the following queries: (A) what are the segmental and syllabic pattern errors made by Kurdish students in their pronunciation? (B) Can the problematic areas in pronunciation be predicted by a systematic comparison of the sound systems of both native and target languages? (C) Can there be any consistency between the predictions and the results of the error analysis experiments in the same field?

To reach the goals of the study the following steps were taken; 1.The sound systems and syllabic patterns of both languages Kurdish and English were clearly described on the basis of place and manner of articulation and the combinatory power of clusters. 2. To carry out a contrastive analysis, the sound segments (vowels, consonants and diphthongs) and the syllabic patterns of both languages were compared in order to surface the similarities and differences. 3. The syllabic patterns and sound segments in English that had no counterparts in Kurdish were detected and considered as problematic areas in pronunciation. 4. To countercheck the acquired predictions, an experiment was carried out with 50 male and female pre-university students.

Subjects were given some passages to read. The readability index of these passages ranged from 8.775 to 10.432 which are quite suitable in comparison to the readability index of pre-university texts ranging from 8.675 to 10.475 . All samples of bound production were transcribed in IPA and the syllabic patterns were shown by symbols ' $\mathrm{V}$ ' and ' $\mathrm{C}$ ' indicating vowels and consonants respectively. An error analysis of the acquired data proved that English sound segments and syllabic patterns with no counterparts in Kurdish resulted in pronunciation errors.

Keywords: segmental errors, syllabic pattern errors, contrastive analysis, error analysis, readability index, IPA, place and manner of articulation, bound oral production, interference, reactive teaching, planned teaching

\section{Introduction}

A learner who consistently mispronounces a range of phonemes can be extremely difficult for a speaker from another language community to understand. This can be very frustrating for the learners who may have a good command of grammar and lexis but may have difficulty in understanding or being understood. A consideration of learners' pronunciation errors and of how these may inhabit successful communication is a useful basis on which to assess why it is important to deal with pronunciation in the classroom learning. For example, when a learner says 'soap' in a situation such as a restaurant where he should have said 'soup' the inaccurate production of a phoneme can lead to misunderstanding at least on the part of the waitress. As one of the main component skills, pronunciation has occupied a place in most English syllabuses and this is why many teachers, researchers and sponsors involved in teaching English as a foreign language have investigated in different ways to find the sources of learner' difficulties in mastering English pronunciation and then to find the best solutions to cope with those difficulties.
\end{abstract}

\section{Review of the Related Literature}

We can define pronunciation in general terms as the production of significant sounds in two senses. First sounds are significant because they are used as part of a code of a particular language. So we can talk about the distinct sounds of different languages. In this sense pronunciation is the production and reception of sounds of speech. Second, sound is significant because it is used to achieve meaning in context of use. Here the code combines with other factors to make communication possible. In this sense we can talk about pronunciation with reference to acts of speaking. The roles of pronunciation in social interaction can be discussed as follows.

1." Pronunciation is closely bound up with social and individual identity. Particular ways of speaking can be seen as an investment in identity, and therefore careful consideration needs to be given to both the feasibility and desirability of forcing learners into a mold of correct pronunciation based on native speakers' norms." (Dalton \& Seidlhofer, 1994)

2. Pronunciation affects intelligibility. Kenworthy, 1995 maintains that what is important for learners is to acquire an accent which is intelligible, or to achieve comfortable intelligibility.

Kelly (2000, p.13) stated; "A lot of pronunciation teaching tends to be done in response to the errors made by students in classroom (Reactive Teaching). Such reactive teaching is absolutely necessary and will always be so. Yet pronunciation work can and should be planed for (Planned Teaching). Teachers should regard features of pronunciation as integral to language analysis and lesson planning. 
Kelly (2000) has divided sample lessons, in regard to pronunciation, into three main types :(A) Integral lessons, in which pronunciation forms an essential part of the language analysis, planning process and the language presentation and practice within the lessons.

(B) Remedial or reactive lessons, where a pronunciation difficulty, which arises in the classroom, is dealt with there and then, in order to facilitate the successful achievement of classroom tasks.

(c)Practice lesson, in which a particular feature of pronunciation is isolated and practiced for its own sake, forming the main focus of a lesson period.

\subsection{Contrastive phonology}

Eliasson, (1989) claims that contrastive phonology compares phonological properties of two languages in order to determine areas in phonological system of one language which may create learning difficulties for speakers of the other language. Kohler (1984) also believes that the aim of contrastive phonology seems to be straight forward and logical: it is to analyze the differences in sound structure between languages and thus lay the foundation for a systematic and illuminating error analysis and correction of pronunciation in foreign language learning. Yarmohammadi (1996) defines contrastive phonology as a process of comparing and contrasting the phonological systems of languages to formulate their differences and similarities. He also believes that Eliasson's \& Kohler's definitions entail that in a pedagogical (or applied) contrastive analysis differences between the two systems are emphasized and similarities are somewhat put aside.

"Contrastive analysis was more successful in phonology than other areas of language studies "(Keshavarz, M.H. 1999). Richard, 1971 also provides the same kind of claim: "On the phonological level even the severest critics of contrastive analysis hypothesis acknowledge the predictive validity of this discipline". As Krezeszowski (1990) states by referring to Halide et al (1964) "a classical contrastive analysis consists of three steps, not always clearly distinguishable in the analysis itself but always tacitly assumed: (1) Description; (2) Juxtaposition; and (3) Comparison.

\subsection{Phonological Errors}

According to Keshavarz (1999) one of the obvious cases of mother tongue interference is in the area of pronunciation. Learners tend to transfer the pronunciation features of their native language to the sound system of the target language. Four major types of phonological errors are as follow: (A) Errors may be due to lack of certain target language phonemes (vowels and consonants) in the learner's mother tongue. (B) Errors caused by differences in the syllabic structures of two languages. (C) Another source of errors is spelling pronunciation of words i.e. learners tend to pronounce words as they are spelled. (D) The fourth source of pronunciation errors is the problem of silent letters i.e. in English; certain letters are spelled out but not pronounced. This may cause errors as EFL learners tend to pronounce these silent letters. In this study phonological errors due to the lack of certain target language phonemes (vowels and consonants) in the learners' mother tongue and also errors caused by the differences in the syllabic structure of the two languages (Kurdish\& English) were investigated. In so doing the outcomes of the contrastive analysis of these languages were taken into consideration.

2.3 Related studies in this area

(a) A contrastive phonological analysis of English and Persian by Dr. Lotfollah Yarmohammadi (1996).

(b) An article on pronunciation problems of Iranian students learning English by Dr. Akbar Mirhassani published in IRAL, VOL. XXI/4. November 1983.

(c) An article on the phonological system and syllabic patterns of Kurdish in Sanandaj by Dr. Gholam Hossein Karimi Doostan (1372).s

(d) A survey of the phonological errors made by Iranian students in their speech by Mahbuobeh Asasi as a thesis for partial fulfillment of the requirements for a degree of Masters of Arts on November 22, 1985.

\section{Method}

\subsection{Subjects}

Fifty pre-university students who were native speakers of Kurdish participated as subjects in this study. They were chosen randomly from two pre-university centers in Kamyaran which is located in Kurdistan Province. Twenty five students were female and the other twenty five were chosen from among male students. The subjects were homogeneous as far as their first term English exam was concerned. The age range of subjects was from 18 to 20 and they all took part quite interestingly and cooperatively in this study.

\subsection{Instrumentation}

The instrumentation used in this study was a bound oral production test including different passages to be read aloud by subjects. Some of the passages were taken from Preparatory English Course books one and two while the other passages were taken from "Bridging the Gap" published by Educational Measurement and Evaluation Organization with the readability index ranging from 8.755 to 10.432 which corresponded to the readability index of pre-university texts. In order to record their pronunciation, each student was asked to read some paragraphs aloud while his voice was recorded. Having obtained samples of bound oral production, they were phonologically transcribed in IPA. To investigate the syllabic pattern production, subjects" pronunciation was also transcribed using symbols "V" and "C" to represent vowels and consonants respectively.

\subsection{Procedure}

Since this study was carried out within the frameworks of contrastive analysis and error analysis, the following steps were taken to reach the ultimate goal of this study:

Firstly, the sound systems of English and Kurdish were clearly described on the basis of the place \& manner of articulation and the combinatory power of the sound clusters. 
Secondly, to carry out a contrastive analysis, the phonological segments and the syllabic patterns of the two languages under investigation were compared carefully.

Third, the English phonological segments and syllabic patterns that have no counterpart in Kurdish were detected and predicted as problematic zones in speech.

Fourth, to countercheck the predicted outcomes, an experiment was carried out with fifty pre-university male and female students. They read aloud some passages while their pronunciation was recorded. In this way, samples of bound oral production were collected.

Fifth, all the oral samples were phonologically transcribed in IPA and the syllabic patterns produced by Kurdish students were shown using symbols "V" and "C".

Finally, on the basis of the acquired data, an error analysis was carried out. The phonological errors were detected, analyzed and computed to give a hierarchy of errors. The goal was to detect whether the outcomes of the contrastive analysis match the predictions or not.

3.4 Data analysis and interpretation

The descriptive statistics applied in the analysis of the data indicated the frequency occurrence of the sound segments and syllabic pattern errors do to their sources (causal factors). The overall results showed that the subjects committed 754 pronunciation errors. 302 errors due to the interference of mother tongue sound segments, 209 due to the spelling pronunciation of words, 83 due to the problem of silent letters and 160 syllabic structure errors due to the differences in the syllable structures of Kurdish and English. We can compute the overall frequencies of errors due to interference of mother tongue (Kurdish) as 462 errors i.e. \%61.27 of the overall students' pronunciation errors.

To compute the CHI- Square, the nominal data was summarized and put into a table with two levels for the dependent variable and four levels for the independent variable.

Table 1. Observed Frequencies

\begin{tabular}{cccccc}
\hline Pronunciation & $x^{1}$ & $x^{2}$ & $x^{2}$ & $x^{4}$ & Row totals \\
\hline$Y^{1}$ & 44 & 38 & 28 & 34 & 144 \\
$Y^{2}$ & 6 & 12 & 22 & 16 & 56 \\
Column totals & 50 & 50 & 50 & 50 & $\mathrm{~N}=200$ \\
& $n^{1}$ & $n^{2}$ & $n^{3}$ & $n^{4}$ & \\
\hline
\end{tabular}

Table 2. Expected Frequencies

\begin{tabular}{lcccc}
\hline Pronunciation & $x^{2}$ & $x^{2}$ & $x^{2}$ & $x^{4}$ \\
\hline$Y^{2}$ & 26 & 26 & 26 & 26 \\
$y^{*}$ & 11.2 & 11.2 & 11.2 & 11.2 \\
\hline
\end{tabular}

$\boldsymbol{x}^{2}=\mathbf{3 5 . 5 5}$ and since in this experiment, there are two rows and four columns, the degree of freedom is three $(\mathbf{d f}=\mathbf{3})$.

\begin{tabular}{cc}
\hline$x^{2}$ & Critical \\
$x^{2}$
\end{tabular}

The ultimate goal of this study was to find adequate answer to the following questions.

1. Is there any interference of Kurdish sound segments and syllabic patterns in the course of learning English by Kurdish students regarding their pronunciation?

2. Is there any consistency between the predictions of contrastive analysis of Kurdish and English sound segments and syllabic patterns and the results of error analysis in the same field?

Based on the above mentioned questions the following null hypotheses were proposed:

1. There is no interference of Kurdish sound segments and syllabic patterns in the course of learning English by Kurdish students regarding their pronunciations.

2. There is no consistency between the predictions of contrastive analysis of Kurdish and English sound segments and syllabic patterns and the results of error analysis in the same field.

Since $\alpha=.05$ has been set for rejecting the null hypotheses and $x^{2}=\mathbf{3 5 . 5 5}$, the null hypothesis of no interference of Kurdish sound segments and syllabic patterns in learning English is definitely rejected. It also proves the consistency between the predictions of contrastive analysis of Kurdish and English sound segments and syllabic patterns and the results of error analysis in the same field.

\section{Conclusion and Implications}

The results indicated that there were similarities between the sound systems of Kurdish and English concerning the vowels, consonants and their clusters. Some sound segments in English had no counterparts in Kurdish and vice versa. The English phonemes with no counterparts in Kurdish were predicted to result in pronunciation errors, which were experimentally supported. 
The combination of the sound segments showed some similarities too; however, some sound segment combinations in English had no counterparts in Kurdish, e.g. "VV" combinations in all positions and initial "CCC" combinations in monosyllabic words. Most of these absent sound clusters were experimentally supported to be problematic and result in pronunciation errors.

The results of the error analysis manifested a rather high frequency of the sound segment and syllabic pattern errors due to the interference of Kurdish in their learning of English. Another important conclusion is that Kurdish students try to reconstruct the absent sound clusters by inserting a vowel before or between the absent clusters. For instance, they tend to pronounce the word 'strict' as /setrict/ or /estrict/.

And finally it was experimentally confirmed that there are four major types of phonological errors as follows:

1. Errors due to the interference of mother tongue sound segments. These happen when the subjects' mother tongue lacks certain target language phonemes for example, pronouncing "then" as /den/ and /zen/ by most of the Kurdish students.

2. Errors due to the interference of mother tongue syllable structures in the target language. They happen when some sound clusters are not permitted in the mother tongue while they are available in the target language, e.g. they tend to pronounce the word 'strict' as /setrict/ or /estrict/.

3. Errors due to the spelling pronunciation of words. Kurdish students sometimes tend to pronounce words as they are spelled, e.g. "blood" is pronounced as /blu:d/.

4. Errors due to certain letters spelled out but not pronounced (silent letters). This caused a lot of problems for Kurdish learners. For instance, they tend to pronounce 'lamb' as /læmb/.

The outcomes of this study can be a valuable source of information for those teachers who are concerned with teaching English as foreign language in general and those involved in teaching English to Kurdish students in particular. This study points out that on the phonological level, the predictive validity of contrastive analysis in locating Kurdish learners' pronunciation errors is unquestionable and teachers can rely on the outcomes of contrastive analysis of the mother tongue and the target language in designing pronunciation exercises for Kurdish learners. It lets them expect certain pronunciation errors since they know the major sources of these errors and act, provide educational materials and teach accordingly. The same procedures may be applied for the native speakers of other languages (Persian, Arabic, Turkish, etc.) by contrasting the sound segments and phonological features of these languages and English.

\section{References}

Asasi, M. (1985). A survey of the phonological errors made by Iranian students in their speech, Tehran: Tehran University M.A. thesis.

Dalton, C. \& B. Siedihofer (1994). Pronunciation. Oxford: Oxford University press.

Eliasson, S. (1984). "Toward a theory of contrastive phonology" in S. Eliasson (ed). Theoretical issues in contrastive phonology. Heidelberg: Julius Groosverlag.

Jones, D. (1992). The pronunciation of English $\left(8^{\text {th }} \mathrm{ed}\right)$. Cambridge: Cambridge University press.

Karimi Doostan, G. (1992). Sanandaji Kurdish Sound System Persian Linguistics Journal, Vol. 10, No.1. pp.55-62.

Kelly, G. (2000). How to teach pronunciation. London: Longman. Pp.11-15.

Keshavarz, M.H. (1997). A practical course of English Phonetics and Phonology. Tehran: SAMT Publications.

Kenworthy, J. (1990). Teaching English Pronunciation. London: Longman Publishing Company.

Mirhassani, A. (1983). Pronunciation Problems of Iranian Students Learning English. IRAL, XXI (4), pp. $220-229$.

Moghedem, A. (1967). Ferbuni Zimanekurdi. Arbil: Kurdestan.

Noormohammadi, I. (1988). A Contrastive Analysis of Cohesion in English and Persian. Shiraz: Shiraz University M.A. Thesis.

Rizgar, B. (1993). Kurdish- English, English- Kurdish Dictionary. London: Longman.

Roach, p. (1991). English Phonetics and Phonology. Cambridge: Cambridge University Press.

Yarmohammadi, L. (1969a). English Consonants and Learning Problems for Iranians: A contrastive Sketch. TESOL Quarterly, Vol.3, No3 pp.231-236. Journal of English as a second Language, Vol.4

Yarmohammadi, L. (1969b). Problems for Iranians in Learning English Vowels: Journal of English as a Second Language, Vol.4, No2, pp.57-67.

Yarmohammadi, L. (1970c). A Note on Contrastive Analysis: English Language Teaching, Vol.25, No.1, pp. 76-79. Yarmohammadi, L. and R. Cowan (1988d). The style of Spoken Persian and the Avoidance of Homonyms Principal: Archive Oriental, Vol.56. pp.346-351.

Yarmohammadi, L. \& G, Pouretedal (1990). A course in English Pronunciation: A Generative Frame work. Tehran: SAMT publications. 